\title{
Pumice as Precursor in Geopolymer Paste and Mortar
}

\author{
Nihat Kabay, Mumin Mert, Nausad Miyan, Tarik Omur \\ Yildiz Technical University, Department of Civil Engineering, Construction Materials Division, 34220, Istanbul, \\ Turkey \\ E-mail:nkabay@yildiz.edu.tr
}

Received: 12 June 2021; Accepted: 23 July 2021; Available online: 25 August 2021

\begin{abstract}
Natural rocks of magmatic origin are alternative precursors in alkali-activated materials and provide opportunities in the search for more environmentally friendly binders compared to portland cement. The pumice is one of these rocks and its amorphous structure and chemical composition make it one of the candidates as a precursor in producing geopolymer binder when finely ground. Since the majority of the pumice reserves are located in Turkey increases its potential utilization in this area, even more. This paper evaluates the physical, mechanical, and microstructural properties of geopolymer pastes and mortars manufactured with pumice powder (PP) and ground granulated blast furnace slag (BFS) with the activating agents sodium hydroxide (NaOH), potassium hydroxide $(\mathrm{KOH})$, and sodium silicate (SS) solution. The experimental results showed that the compressive strength of the geopolymer pastes was mainly affected by the activator concentration and the PP ratio, rather than the activator type, for single activator mixes. However, the incorporation of SS changed this trend as the $\mathrm{KOH}$ and SS combination resulted in higher compressive strength compared to the $\mathrm{NaOH}$ and SS. The gradual increase of the PP ratio in the mix design decreased the density and thermal conductivity, on the other hand, increased the water absorption values of the geopolymer mortars. However, the physical properties were insignificantly changed in geopolymer mortars incorporating 60, 70, and 80\% of PP in the binder.
\end{abstract}

Keywords: Geopolymer; Pumice powder; Blast furnace slag; Compressive strength; Microstructure.

\section{Introduction}

Concrete is utilized more extensively throughout the world on a volume basis than any other engineered material because of its indispensable role in the construction industry. Cement production, the essential ingredient in concrete, accounts for about 5-8\% of all other anthropogenic $\mathrm{CO}_{2}$ emissions [1,2]. In addition, concrete industries are experiencing challenges due to a limited supply of raw materials in response to meet the growing need for cement and concrete. The current annual production of portland cement has reached approximately 4.1 billion metric tons worldwide [3] even though each ton of portland cement production leads to about 0.94 tons of $\mathrm{CO}_{2}$ emissions [4], and cement manufacturing involves an energy-intensive process requiring high thermal energy for calcination to occur [5]. This large-scale production of portland cement has led to both the rapid consumption of energy, natural resources and the emergence of various environmental challenges.

The cement manufacturing industry has started to acknowledge the importance of alternative binders in a carbon-constrained industry, provided that there are substantial reductions in $\mathrm{CO}_{2}$ emissions along with enhanced performance only offered by these alternative binding systems [6] such as geopolymers. Davidovits first introduced geopolymers as inorganic materials rich in silicon ( $\mathrm{Si}$ ) and aluminum (Al). Geopolymers are synthesized by the reaction of a solid aluminosilicate powder with highly concentrated aqueous alkali hydroxide or alkali silicate solution [7]. The range of reported $\mathrm{CO}_{2}$ values for geopolymer concrete compared with portland cement is significant, with an estimate of up to $80 \%$ less than the portland cement $[8,9]$.

In general, the raw materials (also known as the precursors) used in the production of geopolymer binders are blast furnace slag [10-13], fly ash [11,14,15], metakaolin [15-18], waste glass powder [19], clay [20,21], natural pozzolans [22], and other aluminosilicate materials but studies on the utilization of other potential types of precursors for geopolymerization such as pumice powder (PP) which is rich in Si and Al are limited compared to that of other precursors such as metakaolin, blast furnace slag, and fly ash.

Pumice is a natural lightweight material produced by releasing gases during the solidification of lava during volcanic activity. The porous structure of pumice is due to the formation of bubbles or air voids when gases contained in the molten lava flowing from volcanoes are entrapped on cooling [23]. About $40 \%$ of world pumice reserves are present in Turkey [24] which provides several opportunities for its efficient utilization in concrete generally as a lightweight aggregate [25-28] or as a cement replacement material [23,24,29,30]. 
The scientific research papers on the utilization of PP as a precursor in geopolymer binders are limited but increasing in recent years. Safari et al. [31] studied the mechanical properties of pumice-based geopolymer paste with an alkaline solution of sodium hydroxide and sodium silicate cured at different temperatures and durations. They claimed that optimum compressive and flexural strength could be obtained with the alkali solution of concentration $12 \mathrm{M}$ cured at $60^{\circ} \mathrm{C}$ for 120 hours. Occhipinti et al. [32] investigated the geopolymerization of pumice and metakaolin blend, at different weight ratios, activated with sodium hydroxide and sodium silicate solution cured at $25 \pm 3{ }^{\circ} \mathrm{C}$ and concluded that alkali-activated mixture of pumice with metakaolin (20-30 wt\%) performed with appropriate compressive strength than that of pumice only. In addition, pumice can be potentially utilized as light aggregate in the binary mixture with metakaolin to obtain structural elements with low dry unit weight and well accessible porosity, they further added. Allahverdi et al. [33] studied pumice-based geopolymer paste activated with an alkaline solution of $\mathrm{NaOH}$ and SS with various silica moduli and $\mathrm{Na}_{2} \mathrm{O}$ concentrations and found a relatively high compressive strength up to $47 \mathrm{MPa}$ at the age of 28 days.

The present study aims to contribute to the knowledge on the PP-based geopolymer materials by investigating the effect of alkali activator type and concentration as well as the PP and BFS mix ratio on the physical, mechanical and microstructural properties of ambient cured geopolymer paste and mortar.

\section{Materials and methodology}

\subsection{Materials}

The pumice used in this study was supplied from Nevşehir city, located in the central Anatolia region of Turkey. The pumice was initially dried in the oven at $105^{\circ} \mathrm{C}$ for 24 hours and then mechanically ground by using a disc grinder. The BFS was obtained from a local steel manufacturing company in Turkey. The appearance and the chemical composition of PP and BFS are shown in Fig. 1 and Table 1, respectively. The PP is highly siliceous, and according to ASTM C618, it could be considered as a comparatively reasonable natural pozzolan based on its chemical composition. Fig. 2 displays the X-Ray Diffraction (XRD) patterns of PP and BFS showing that both of the materials are mainly amorphous in structure. Furthermore, the SEM micrographs of PP and BFS are presented in Fig. 3 which show that the PP is distinguished with its hollow structure and comparatively coarser particles compared to BFS. The specific gravity of PP and BFS were determined as 2.34 and 2.91, respectively. Siliceous sand with a particle density of $2.67 \mathrm{~g} / \mathrm{cm}^{3}$ was used as fine aggregate in the mortar mixes. The particle size distribution of PP, BFS, and sand are presented in Fig. 4 which clearly shows that the BFS was finer than the PP, with a median particle size $\left(d_{50}\right)$ of $9.93 \mu \mathrm{m}$ compared to $26.3 \mu \mathrm{m}$. The activation of the binders was performed using sodium hydroxide $(\mathrm{NaOH})$, potassium hydroxide $(\mathrm{KOH})$, and sodium silicate solution (SS) as the alkaline activators. The properties and purity of the alkaline activators are shown in Table 2. NaOH and KOH pellets had densities of $2.13 \mathrm{~g} / \mathrm{cm}^{3}$ and $2.04 \mathrm{~g} / \mathrm{cm}^{3}$ respectively. SS used in the present study had a silica modulus $\left(\mathrm{SiO}_{2} / \mathrm{Na}_{2} \mathrm{O}\right)$ of 3.3 and a density of $1.35 \mathrm{~g} / \mathrm{cm}^{3}$. The chemically bound $\mathrm{Na}_{2} \mathrm{O}$ and $\mathrm{SiO}_{2}$ in $\mathrm{SS}$ were $8.4 \%$ and $27.8 \%$ respectively as per the information provided by the supplier.
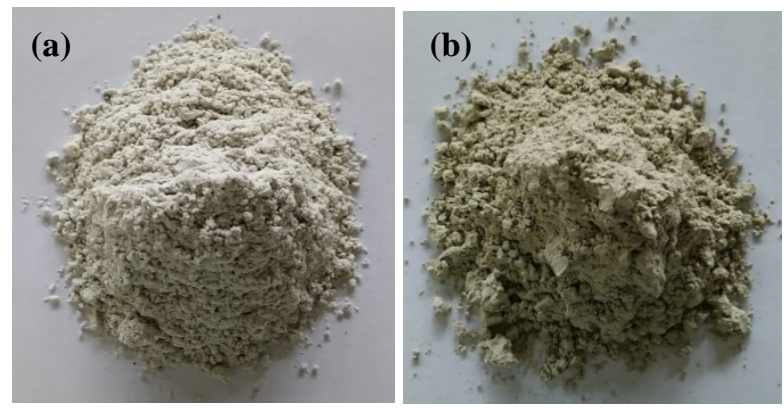

Fig. 1. The appearance of (a) PP and (b) BFS

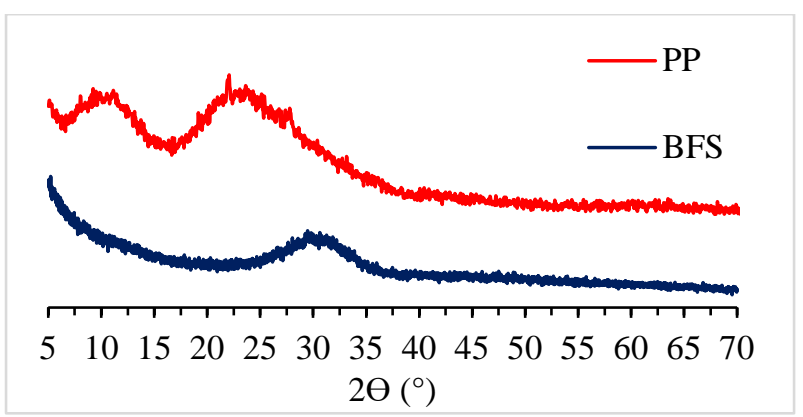

Fig. 2. XRD patterns of $\mathrm{PP}$ and BFS 
Table 1. Chemical compositions of PP and BFS

\begin{tabular}{lcc}
\hline Chemical composition (\%) & PP & BFS \\
\hline $\mathrm{CaO}$ & 0.10 & 37.50 \\
$\mathrm{SiO}_{2}$ & 77.52 & 39.00 \\
$\mathrm{Al}_{2} \mathrm{O}_{3}$ & 12.99 & 12.50 \\
$\mathrm{Fe}_{2} \mathrm{O}_{3}$ & 1.50 & 1.00 \\
$\mathrm{MgO}$ & 0.40 & 5.00 \\
$\mathrm{Na}_{2} \mathrm{O}$ & 0.12 & 0.60 \\
$\mathrm{~K}_{2} \mathrm{O}$ & 0.95 & 0.20 \\
$\mathrm{SO}_{3}$ & 0.52 & 0.20 \\
Loss on ignition & 5.42 & 0.02 \\
Specific gravity & 2.34 & 2.91 \\
Specific surface (Blaine, $\left.\mathrm{cm}^{2} / \mathrm{g}\right)$ & - & 5300 \\
\hline
\end{tabular}
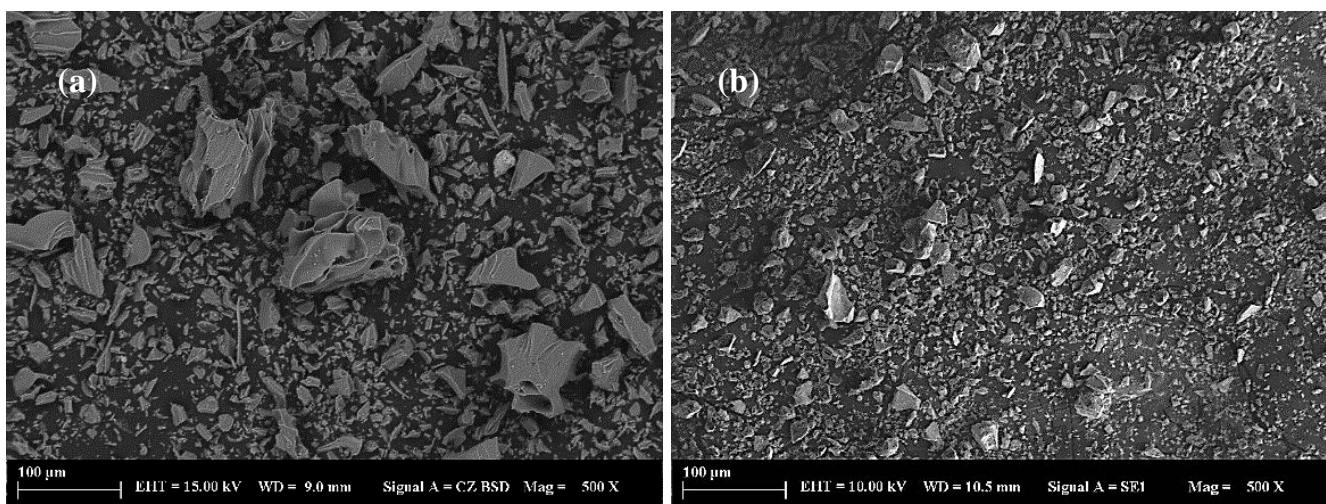

Fig. 3. SEM micrographs of (a) PP and (b) BFS

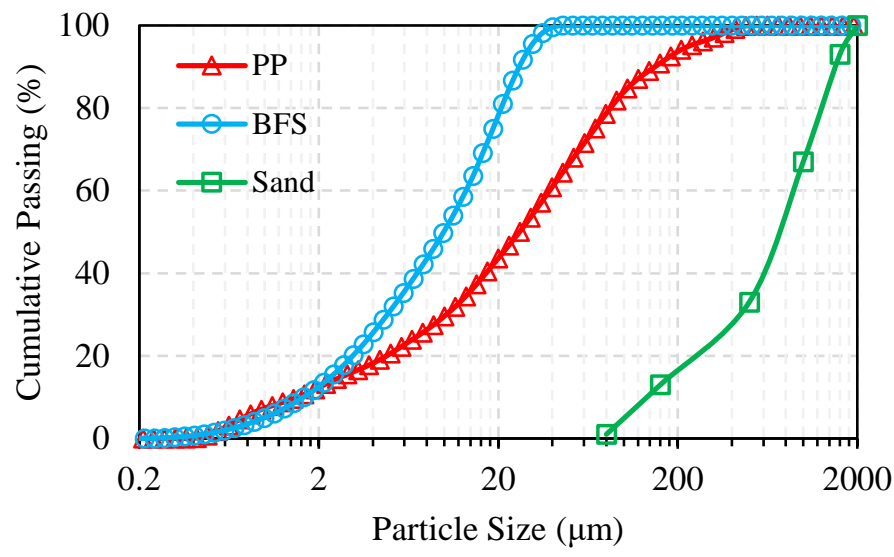

Fig. 4. Particle size distribution of PP, BFS, and sand

Table 2. Properties of alkaline activators

\begin{tabular}{lllr}
\hline Properties & $\begin{array}{l}\text { Sodium } \\
\text { hydroxide }\end{array}$ & $\begin{array}{l}\text { Potassium } \\
\text { hydroxide }\end{array}$ & $\begin{array}{r}\text { Sodium silicate } \\
\text { solution }\end{array}$ \\
\hline Molecular formula & $\mathrm{NaOH}$ & $\mathrm{KOH}$ & $\mathrm{Na}_{2} \mathrm{SiO}_{3}$ \\
Molecular weight $(\mathrm{g} / \mathrm{mol})$ & 40.00 & 56.11 & 122.06 \\
Appearance & Solid & Solid & $\mathrm{Gel}$ \\
$\mathrm{pH}$ & $>14.0$ & 13.5 & $11.0-11.5$ \\
$\mathrm{Relative} \mathrm{density}\left(\mathrm{g} / \mathrm{cm}^{3}\right)$ & 2.13 & 2.04 & 1.35 \\
$\mathrm{Na}_{2} \mathrm{O}(\%)$ & - & - & 8.4 \\
$\mathrm{SiO}_{2}(\%)$ & - & - & 27.8 \\
$\mathrm{H}_{2} \mathrm{O}(\%)$ & - & - & 63.8 \\
\hline
\end{tabular}




\subsection{Mix proportions}

Geopolymer pastes were prepared with alkaline solutions $\mathrm{NaOH}, \mathrm{KOH}$, and mixtures of $\mathrm{NaOH}$ or $\mathrm{KOH}$ with SS. The $\mathrm{NaOH}$ and $\mathrm{KOH}$ pellets were mixed with tap water and left to cool down before mixing. Also, SS solution was added for the mixes that contained SS. The mix proportions of pastes and mortars are depicted in Table 3 . The total water content in the relevant mixes was corrected by deducing the chemically bound water present in the SS. All geopolymer pastes contained $80 \%$ of PP by mass, and the remaining $20 \%$ was BFS. The notations for addressing the mixes along with their definitions are shown in Table 4 for some mixes. A total of 16 mixes, including paste and mortar samples, were prepared. The water-to-binder (w/b) ratio was 0.34 for all paste mixes, and the molarity of $\mathrm{NaOH}$ and $\mathrm{KOH}$ varied as 4,6 , and 8 . The samples containing SS can be identified separately with the notation "SS" in which the number followed by SS denotes the ratio of SS to $\mathrm{NaOH}$ or $\mathrm{KOH}$ pellets by mass (Table 4).

The mortar samples were prepared with the alkaline solution containing KOH and SS, in which the ratio of SS to $\mathrm{KOH}$ pellets by mass was constant as 1.0 , and the concentration of $\mathrm{KOH}$ was kept constant as $6 \mathrm{M}$. The geopolymer mortars contained 50 to $80 \%$ of PP by mass, and the remaining was BFS. In addition, the binder and the sand fractions were $50 \%$ each by volume, and the w/b ratio was 0.50 in all mortar mixes.

Table 3. Mix proportions $\left(\mathrm{kg} / \mathrm{m}^{3}\right)$

\begin{tabular}{|c|c|c|c|c|c|c|c|}
\hline \multirow{2}{*}{ Material } & \multirow{2}{*}{ Specimen ID } & \multicolumn{2}{|c|}{ Binders } & \multirow{2}{*}{ Sand } & \multicolumn{3}{|c|}{ Alkaline activators } \\
\hline & & PP & BFS & & $\mathrm{NaOH}$ & $\mathrm{KOH}$ & SS \\
\hline \multirow{12}{*}{$\begin{array}{l}\text { Geopolymer } \\
\text { paste }\end{array}$} & $\mathrm{P}-4 \mathrm{~N}$ & 1070 & 268 & - & 73 & - & - \\
\hline & P-6N & 1070 & 268 & - & 109 & - & - \\
\hline & P-8N & 1070 & 268 & - & 146 & - & - \\
\hline & $\mathrm{P}-4 \mathrm{~K}$ & 1070 & 268 & - & - & 102 & - \\
\hline & P-6K & 1070 & 268 & - & - & 153 & - \\
\hline & P-8K & 1070 & 268 & - & - & 204 & - \\
\hline & P-4N-SS1.0 & 1070 & 268 & - & 73 & - & 73 \\
\hline & P-6N-SS1.0 & 1070 & 268 & - & 109 & - & 109 \\
\hline & P-8N-SS1.0 & 1070 & 268 & - & 146 & - & 146 \\
\hline & P-4K-SS1.0 & 1070 & 268 & - & - & 102 & 102 \\
\hline & P-6K-SS1.0 & 1070 & 268 & - & - & 153 & 153 \\
\hline & P-8K-SS1.0 & 1070 & 268 & - & - & 204 & 204 \\
\hline \multirow{4}{*}{$\begin{array}{l}\text { Geopolymer } \\
\text { mortar }\end{array}$} & M50 & 284 & 284 & 1335 & - & 96 & 96 \\
\hline & M60 & 337 & 225 & 1335 & - & 96 & 96 \\
\hline & M70 & 390 & 167 & 1335 & - & 96 & 96 \\
\hline & M80 & 441 & 110 & 1335 & - & 96 & 96 \\
\hline
\end{tabular}

Table 4. Mix notations and definitions for some mixes

\begin{tabular}{ll}
\hline Mix ID & Definition \\
\hline P-4N & Paste sample containing 4M NaOH \\
P-6K & Paste sample containing 6M KOH \\
P-4N-SS1.0 & Paste sample containing 4M NaOH and SS-to-NaOH ratio 1.0 \\
P-4K-SS1.0 & Paste sample containing 4M of KOH and SS-to-KOH ratio 1.0 \\
M50 & Mortar sample in which PP replaces BFS 50\% by mass \\
\hline
\end{tabular}

\subsection{Mixing, curing, and preparation of test specimens}

The alkaline solution was prepared before the mixing and poured into the precursor blend containing PP and BFS to obtain the geopolymer paste samples. During mortar mixing, the sand was introduced steadily after $30 \mathrm{~s}$ of paste mixing. The mixing continued for about 3 minutes to obtain a homogenous mix. The cubic specimens of dimensions $50 \times 50 \times 50 \mathrm{~mm}^{3}$ were produced for the compressive strength test of both paste and mortar. Furthermore, cylindrical specimens of $200 \mathrm{~mm}$ in height and $100 \mathrm{~mm}$ in diameter were prepared to determine the physical properties of the mortars. Prism specimens with dimensions of $120 \times 60 \times 30 \mathrm{~mm}^{3}$ were manufactured to determine the thermal conductivity coefficient of the mortar mixes. The fresh paste or mortar was poured into the relevant molds and wrapped with plastic film to prevent evaporation. The specimens were kept in the laboratory for $24 \mathrm{~h}$ before demolding. The demolded specimens were then transferred and stored in the humidity cabinet in which the temperature and the relative humidity (RH) were constant as $21 \pm 1^{\circ} \mathrm{C}$ and $55 \pm 2 \%$ until the specified testing ages. It is important to mention that, during mixing, the workability of the paste samples significantly reduced with 
increased $\mathrm{NaOH}$ molarity. On the other hand, an opposite trend was noticed where the workability of the paste samples improved with increased $\mathrm{KOH}$ concentration.

\subsection{Testing procedure}

\subsubsection{Mechanical and physical tests}

The compressive strength test of the paste and mortar mixes was performed on the $50 \mathrm{~mm}$ cubic specimens in accordance with ASTM C109. Three samples were tested for each mix at 3, 7, and 28 days and the average values were recorded.

The physical properties of the mortar mixes were determined at the age of 28 days on the cylindrical specimens (100 $\mathrm{mm}$ in diameter), cut into a height of $50 \mathrm{~mm}$. The tests were conducted on 3 samples for each mix and the average was recorded. The water absorption, oven-dry density, and voids content of the samples were determined following the BS 1881 and ASTM C642 standards and using the following equations.

$$
\begin{aligned}
& \text { Water absorption }(\%)=\frac{\left(B_{1} \text { or } 2-A\right)}{A} \times 100 \\
& \text { Oven }- \text { dry density }=\frac{A}{(C-D)} \\
& \text { Voids content }(\%)=\frac{(C-A)}{(C-D)} \times 100
\end{aligned}
$$

In these equations $A$ represents the oven-dry mass, $B_{1}$ and $B_{2}$ represents the saturated surface dry mass after immersion in water for 30 minutes and 48 hours respectively, $C$ represents the soaked, boiled, and surface-dried mass, and $D$ represents the apparent mass of the specimens in water after immersion and boiling.

The thermal conductivity test was performed on prismatic mortar samples. Three samples were used for each mix to determine the thermal conductivity coefficient using a quick thermal conductivity meter, QTM 500 instrument (Kyoto Electrics, Japan), with a measuring range of $0.023-12.0 \mathrm{~W} / \mathrm{mK}$. The precision and reproducibility of the instrument are reported as $\pm 5 \%$, and $\pm 3 \%$, respectively. QTM-500 follows the hot wire methodology described in ASTM C 1113, which has been used to determine the thermal properties of several materials [34-36]. During the test, an impulse of thermal flow is supplied into the sample with a heating hot wire installed in the measuring probe. The probe is then pressed on the flat surface of the test sample. The temperature rise is registered with a thermistor, and the thermal conductivity is calculated from the test data acquired from the measuring probe [37].

\subsubsection{Microstructural analysis}

PANalytical X'Pert PRO diffractometer which uses $\mathrm{Cu}$ tube radiation was employed to identify the phase compositions of the selected paste samples at the age of 28 days. The X-Ray Diffractometer (XRD) patterns were collected in the scan range of $5-90^{\circ}(2 \theta)$, and with a step size of $0.017^{\circ}$. Zeiss EVO ${ }^{\circledR}$ LS 10 SEM instrument (Carl Zeiss Microscopy GmbH, Germany) equipped with energy dispersive spectroscopy (SEM-EDS) was used to characterize the microstructure and determine the chemical composition of the selected paste samples after $28 \mathrm{~d}$ of hydration.

\section{Results and discussion}

\subsection{Compressive strength}

The compressive strength of the geopolymer paste mixes was investigated using different concentrations of $\mathrm{NaOH}, \mathrm{KOH}$ independently, and in combination with SS, and the results are presented in Figs. 5-6 and Table 5. Test results given in Fig. 5 shows that the mixes containing $4 \mathrm{M}$ of $\mathrm{NaOH}$ and $\mathrm{KOH}$ had the highest compressive strength at the age of 28 days. On the other hand, the mix with $6 \mathrm{M} \mathrm{NaOH}$ concentration had the lowest strength at 28 days, and the mixes with $6 \mathrm{M}$ and $8 \mathrm{M}$ of $\mathrm{KOH}$ solution had comparable compressive strength at all ages.

The effect of the inclusion of SS with varying molarities of $\mathrm{NaOH}$ and $\mathrm{KOH}$ on the compressive strength of geopolymer paste samples are presented in Fig. 6, in which the ratio of SS to $\mathrm{NaOH}$ or $\mathrm{KOH}$ by mass was 1.0. The results showed that the paste mixes containing $\mathrm{KOH}$ and SS alkaline solution had higher compressive strength compared to that of the mixes with $\mathrm{NaOH}$ and SS, and the highest strength at 28 days was observed as $29.0 \mathrm{MPa}$ in P-6K-SS1.0 mix. Consequently, the highest strength-giving alkaline activator combination of $6 \mathrm{M} \mathrm{KOH}$ and $\mathrm{SS} / \mathrm{KOH}$ ratio of 1.0 in the paste mixes were used to manufacture the mortar samples.

The mortar mixes were manufactured with varying ratios of PP from $50 \%$ to $80 \%$ by mass of BFS. The compressive strength results of the mortar mixes are presented in Fig. 7 and Table 6. Test results showed that the 
compressive strength gradually decreased with the increase in PP content, and the compressive strength of the geopolymer mortars ranged from 10.6 to $24.5 \mathrm{MPa}$.
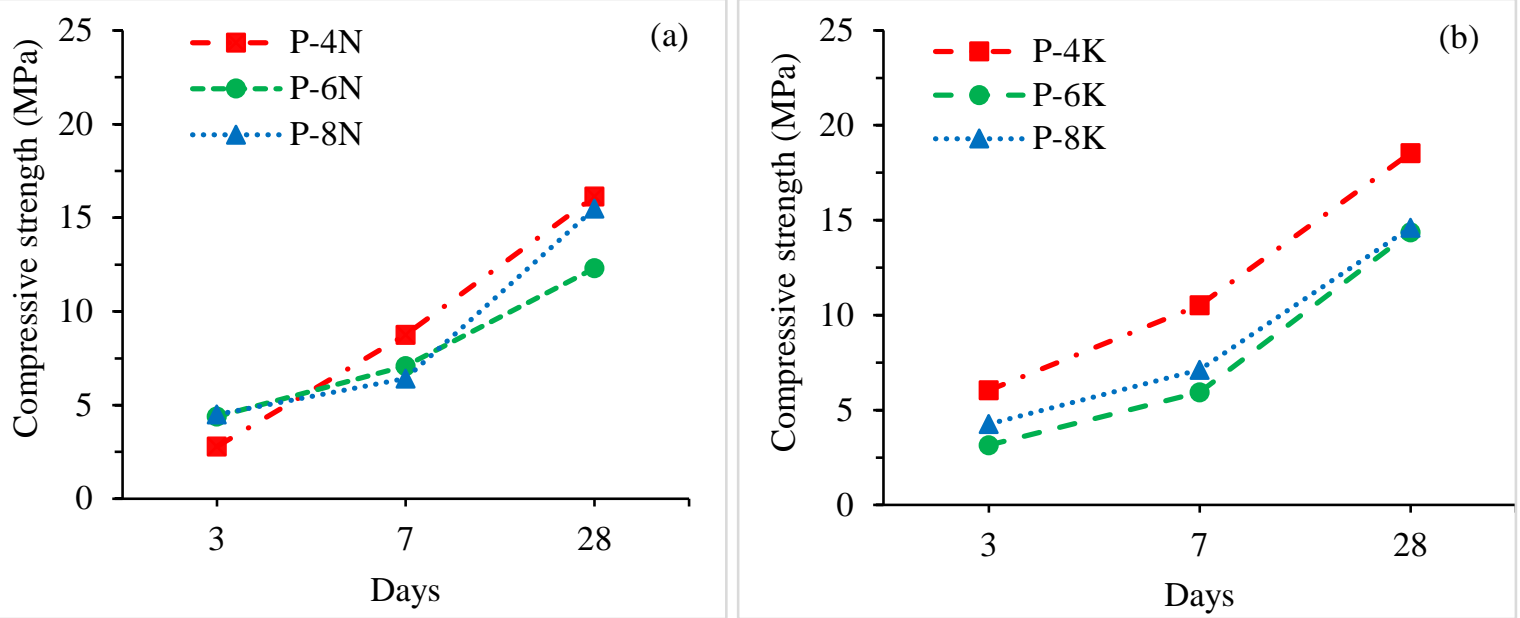

Fig. 5. The compressive strength of paste samples with different concentrations of (a) $\mathrm{NaOH}$ and (b) $\mathrm{KOH}$
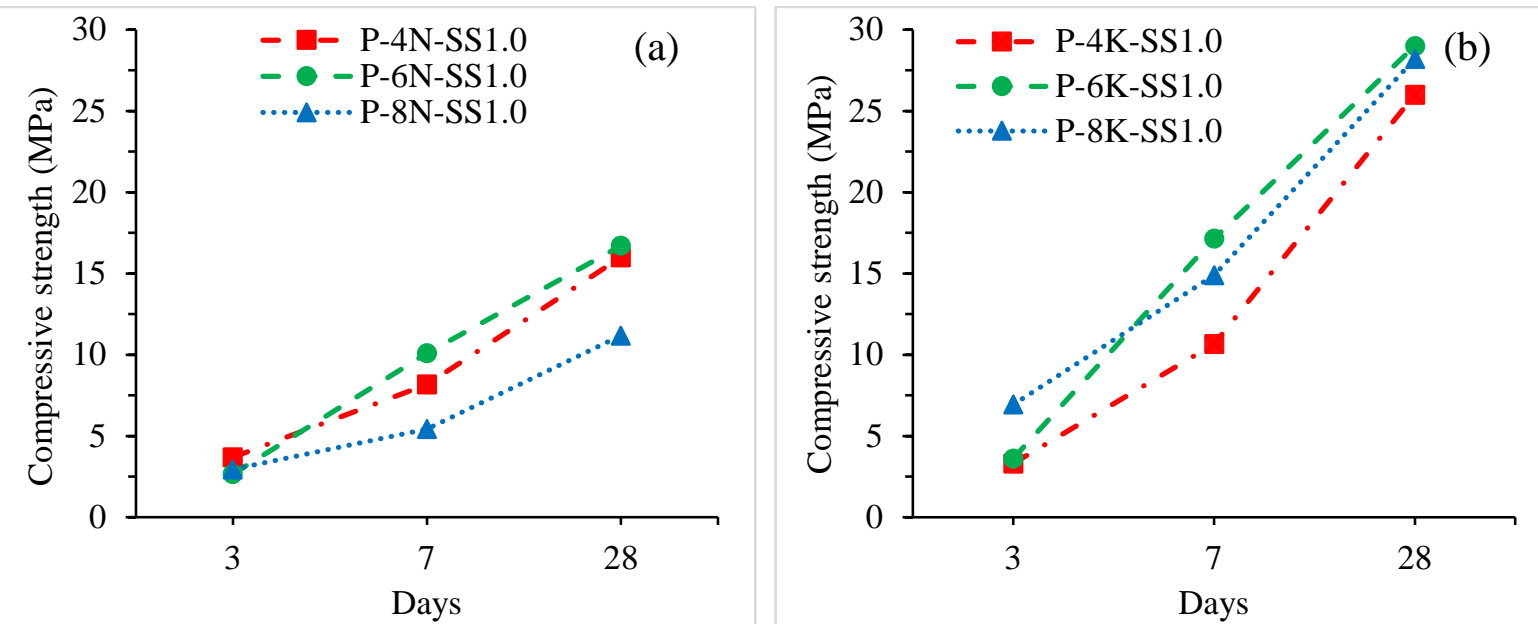

Fig. 6. The compressive strength of paste samples containing SS: (a) The effect of NaOH molarity and (b) The effect of $\mathrm{KOH}$ molarity

Table 5. Compressive strength results of the geopolymer paste mixes

\begin{tabular}{lccc}
\hline \multirow{2}{*}{ Specimen ID } & \multicolumn{3}{c}{ Compressive strength (MPa) } \\
\cline { 2 - 4 } & 3d & $7 \mathrm{~d}$ & $28 \mathrm{~d}$ \\
\hline P-4N & $2.8 \pm 0.4$ & $8.8 \pm 0.2$ & $16.1 \pm 1.1$ \\
P-6N & $4.4 \pm 0.1$ & $7.1 \pm 0.6$ & $12.3 \pm 0.1$ \\
P-8N & $4.5 \pm 0.2$ & $6.4 \pm 0.1$ & $15.5 \pm 0.9$ \\
P-4K & $6.0 \pm 1.1$ & $10.5 \pm 1.1$ & $18.5 \pm 0.1$ \\
P-6K & $3.2 \pm 0.6$ & $5.9 \pm 0.2$ & $14.4 \pm 0.3$ \\
P-8K & $4.3 \pm 0.1$ & $7.1 \pm 0.2$ & $14.6 \pm 1.2$ \\
P-4N-SS1.0 & $3.7 \pm 0.7$ & $8.2 \pm 1.8$ & $16.0 \pm 0.1$ \\
P-6N-SS1.0 & $2.7 \pm 1.0$ & $10.1 \pm 1.1$ & $16.7 \pm 0.8$ \\
P-8N-SS1.0 & $3.0 \pm 0.2$ & $5.4 \pm 0.7$ & $11.2 \pm 0.3$ \\
P-4K-SS1.0 & $3.3 \pm 0.4$ & $10.7 \pm 1.6$ & $26.0 \pm 0.6$ \\
P-6K-SS1.0 & $3.6 \pm 1.2$ & $17.2 \pm 1.1$ & $29.0 \pm 1.9$ \\
P-8K-SS1.0 & $6.9 \pm 0.8$ & $14.9 \pm 0.3$ & $28.2 \pm 1.0$ \\
\hline
\end{tabular}




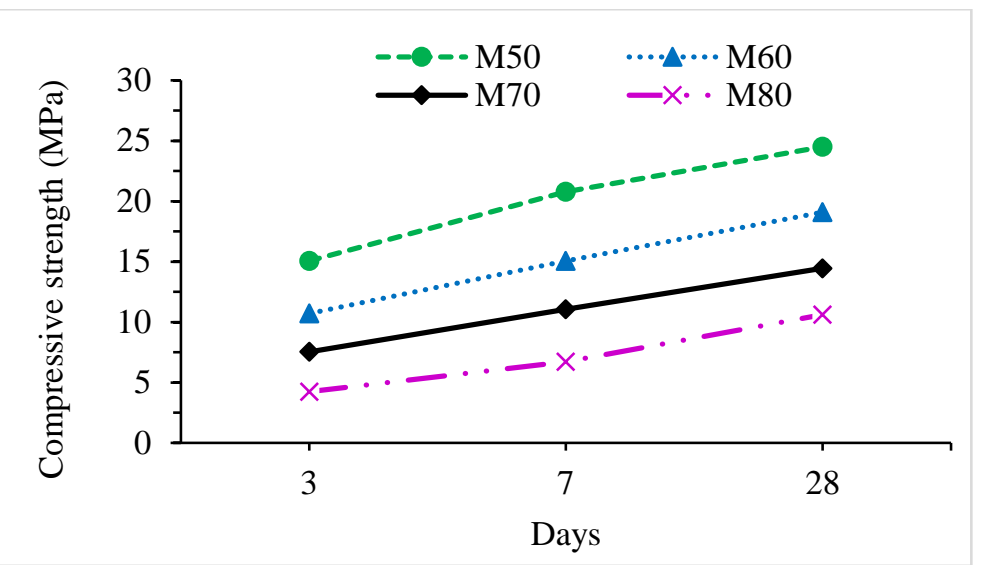

Fig. 7. The compressive strength of geopolymer mortars

Table 6. Compressive strength results of the geopolymer mortar mixes

\begin{tabular}{lccc}
\hline \multirow{2}{*}{ Specimens } & \multicolumn{3}{c}{ Compressive strength (MPa) } \\
\cline { 2 - 4 } & 3d & $7 d$ & $28 d$ \\
\hline M50 & $15.1 \pm 0.4$ & $20.8 \pm 0.3$ & $24.5 \pm 0.7$ \\
M60 & $10.7 \pm 0.1$ & $15.0 \pm 0.1$ & $19.1 \pm 0.1$ \\
M70 & $7.5 \pm 0.1$ & $11.1 \pm 0.1$ & $14.5 \pm 0.5$ \\
M80 & $4.2 \pm 0.2$ & $6.7 \pm 0.2$ & $10.6 \pm 0.1$ \\
\hline
\end{tabular}

\subsection{Oven-dry density, water absorption and voids content}

The oven-dry density, water absorption, and voids content results of the mortar mixes are presented in Table 7 and Fig. 8. The oven-dry density of the geopolymer mortars ranged between 1873 and $1927 \mathrm{~kg} / \mathrm{m}^{3}$. The gradual increment of PP in the mortar decreased the density as revealed in Fig. 8. The water absorption of the mortar mixes was determined at 30 minutes, 48 hours, and after immersion in boiling water. The increase in PP content from 50 to $60 \%$ increased the water absorption values and the voids content. On the other hand, a further increase in the PP ratio slightly altered the water absorption and the other physical properties tested.

Table 7. Physical properties of mortar mixes

\begin{tabular}{cccccc}
\hline Specimens & $\begin{array}{c}\text { Oven-dry } \\
\text { density } \\
\left(\mathrm{kg} / \mathrm{m}^{3}\right)\end{array}$ & $\begin{array}{c}\text { Water absorption } \\
(30 \mathrm{~min}) \\
(\%)\end{array}$ & $\begin{array}{c}\text { Water absorption } \\
(48 \mathrm{~h}) \\
(\%)\end{array}$ & $\begin{array}{c}\text { Water absorption } \\
\text { after boiling } \\
(\%)\end{array}$ & $\begin{array}{c}\text { Voids } \\
\text { content } \\
(\%)\end{array}$ \\
\hline M50 & $1927 \pm 7.0$ & $7.5 \pm 0.2$ & $8.7 \pm 0.2$ & $11.6 \pm 0.1$ & $22.4 \pm 0.1$ \\
M60 & $1894 \pm 7.3$ & $8.5 \pm 0.2$ & $9.2 \pm 0.1$ & $12.7 \pm 0.2$ & $24.0 \pm 0.4$ \\
M70 & $1885 \pm 22.1$ & $8.6 \pm 0.1$ & $9.2 \pm 0.1$ & $12.5 \pm 0.1$ & $23.4 \pm 0.1$ \\
M80 & $1873 \pm 19.7$ & $8.4 \pm 0.4$ & $9.0 \pm 0.4$ & $12.8 \pm 0.5$ & $23.9 \pm 0.7$ \\
\hline
\end{tabular}

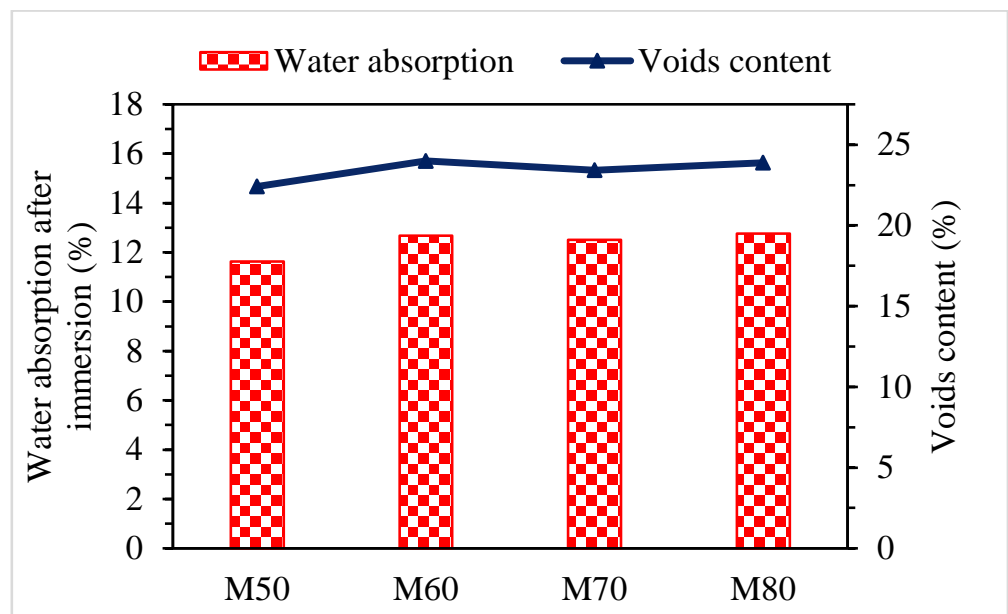

Fig. 8. Water absorption and voids content of mortar mixes 


\subsection{Thermal conductivity}

The thermal conductivity of the mortar mixes is presented in Fig. 9 along with their oven-dry density values. The thermal conductivity of the geopolymer mortar samples decreased consistently with the increment of the PP ratio. The lowest thermal conductivity was observed in the M70 mix as $0.558 \mathrm{~W} / \mathrm{mK}$ which is $45 \%$ lower than the M50 mix. The reason behind the decrement of thermal conductivity might be due to the presence of voids within the PP particles (Fig. 3a) and the increased amount of voids within the mortar matrix compared to the M50 mix (Fig. 8).

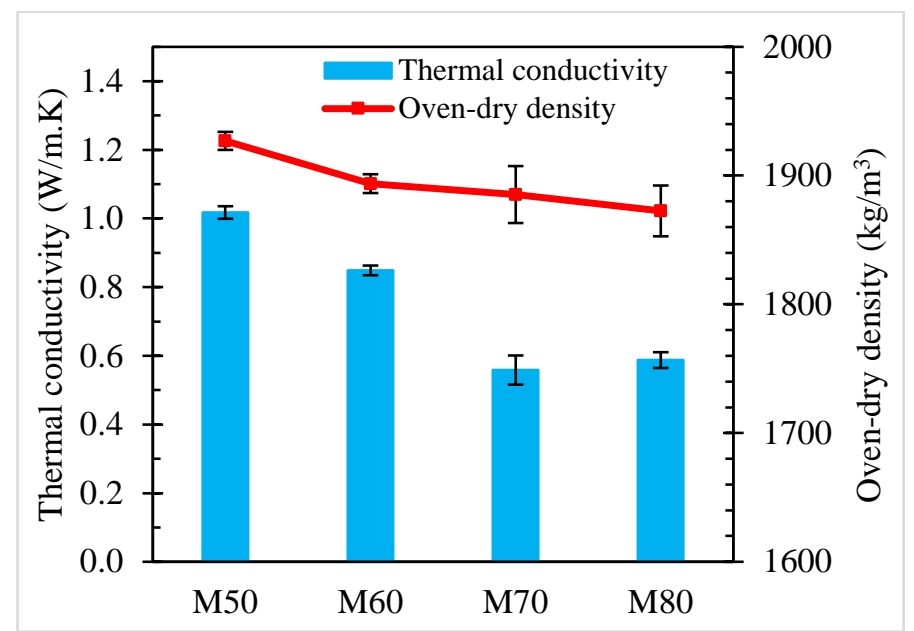

Fig. 9. Thermal conductivity and oven-dry density of mortar mixes

\subsection{Microstructural analysis}

Figs. 10 and 11 show the SEM micrographs of the geopolymer pastes corresponding to the M50 and M80 mortar mixes. The geopolymer pastes show clear signs of unreacted PP particles distributed in the matrix which increase with an increase of PP content in the mix composition. The microstructure of M50 was more homogeneous compared to that of M80 but contained several micro-cracks which might be due to the higher BFS content causing higher shrinkage and cracks [38-41]. Table 8 summarizes the main chemical elements of the paste samples in the analyzed area and their atomic ratios determined from the EDS analysis. The samples predominantly contained Si, $\mathrm{Ca}$, and $\mathrm{K}$ elements indicating that the reaction products of geopolymer pastes consist of the intermixed microstructure of geopolymeric C-A-S-H and K-A-S-H gels. The mix composition of the geopolymer pastes resulted in variation of the detected elements in the scanned area and therefore the structure of the reaction products. The increase in BFS content (M50) mainly increased the Ca and Mg ratio. On the other hand, the increase in PP content (M80) mainly increased the percentage of the Si. The $\mathrm{Ca} / \mathrm{Si}$ and $\mathrm{Si} / \mathrm{Al}$ ratios of M50 were 0.7 and 3.2, and M80 were 0.1 and 5.0, respectively. The increasing $\mathrm{Ca} / \mathrm{Si}$ and $\mathrm{Si} / \mathrm{Al}$ ratios are reported to be favorable in the formation of strength-giving compounds [42,43]. However, the high amount of unreacted PP particles in the analyzed area might be responsible for the higher Si content in M80 which makes it imprecise to correlate with the strength. Furthermore, the reduced $\mathrm{CaO}$ in the powder blend with the increase in PP content, also observed in the EDS spectra of the paste samples, might have hindered the strength development of M80 than that of M50.
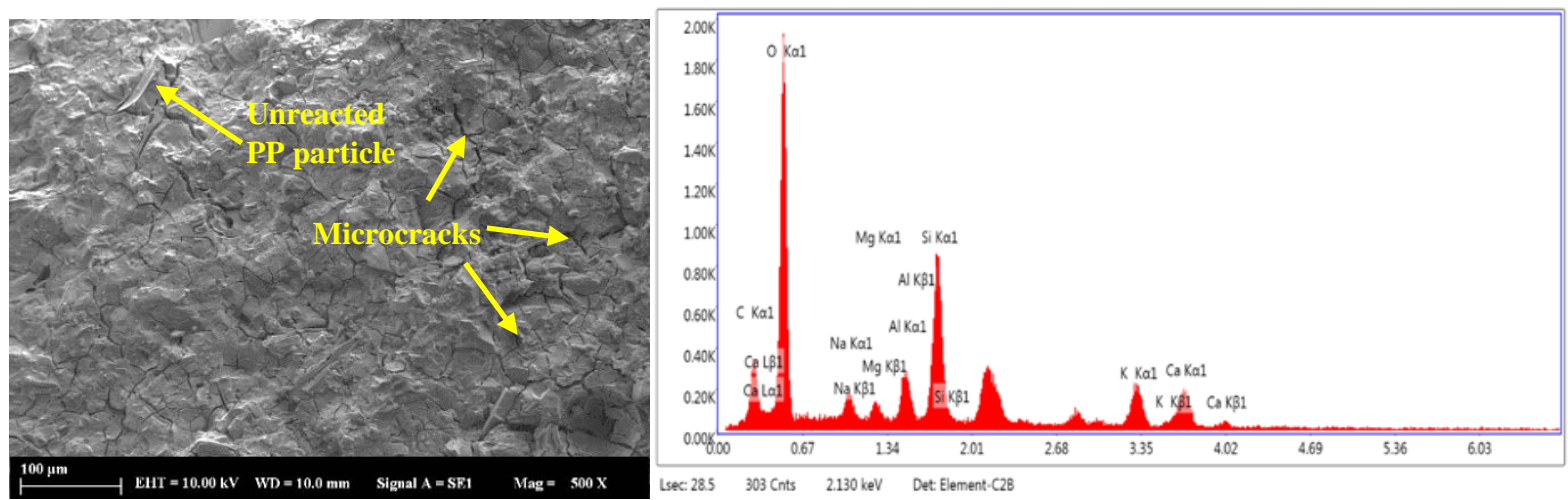

Fig. 10. SEM micrograph and EDS spectra of M50 geopolymer paste 

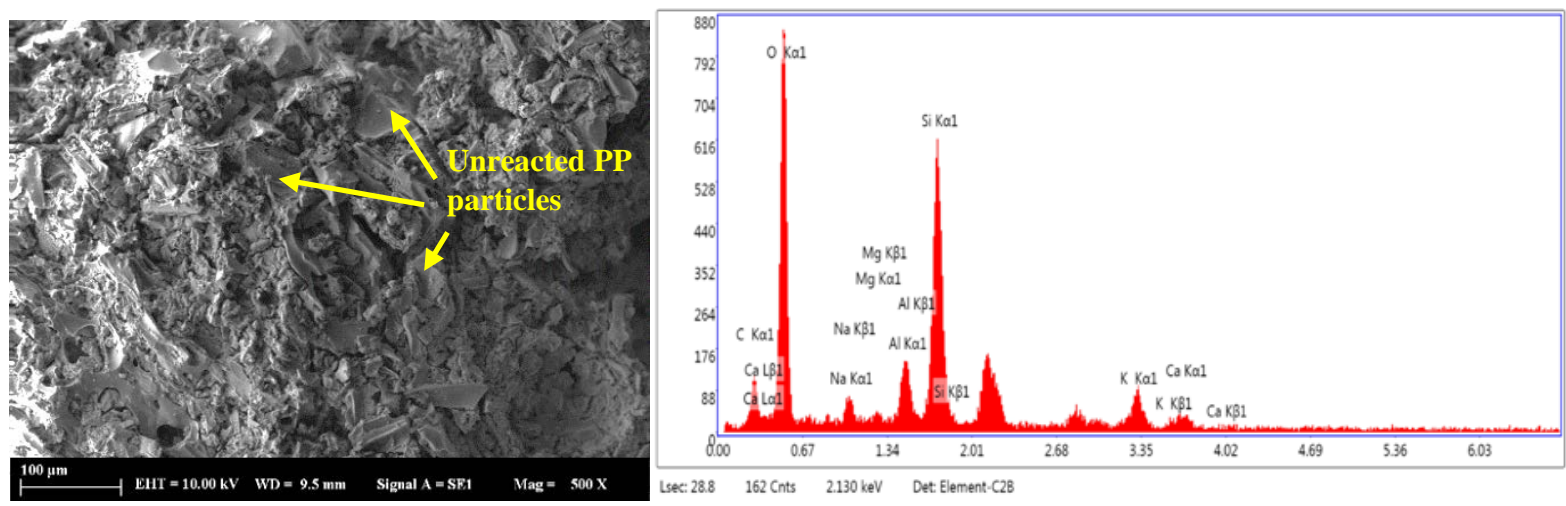

Fig. 11. SEM micrograph and EDS spectra of M80 geopolymer paste

Table 8. EDS analysis results

\begin{tabular}{lcc}
\hline & \multicolumn{2}{c}{ Atomic \% } \\
\cline { 2 - 3 } Element & M50 & M80 \\
\hline NaK & 2.7 & 0.8 \\
MgK & 1.8 & 0.1 \\
$\mathrm{AlK}$ & 4.2 & 4.7 \\
$\mathrm{SiK}$ & 13.5 & 23.7 \\
$\mathrm{KK}$ & 8.1 & 7.0 \\
$\mathrm{CaK}$ & 9.1 & 3.2 \\
$\mathrm{Si} / \mathrm{Al}$ & 3.2 & 5.0 \\
$\mathrm{Ca} / \mathrm{Si}$ & 0.7 & 0.1 \\
\hline
\end{tabular}

The XRD patterns of the geopolymer pastes corresponding to the M50 and M80 mortar samples are shown in Fig. 12. The XRD patterns of the pastes exhibited similar compositions, however, the peak intensities of M50 were slightly higher than that of M80 which can be attributed to the presence of higher BFS in the mix composition of M50. Furthermore, the XRD spectra of the M50 sample showed a broader hump between $20^{\circ}$ and $40^{\circ}$ representing the presence of a more intense geopolymer phase compared to M80. In slag-based geopolymers, C-S-H gel coexists with alumino-silicate compounds (C-(N-)A-S-H) and can be identified by crystalline peak approximately at $29^{\circ}-30^{\circ}[39,44]$. The identified peaks in the geopolymer samples were mainly C-(N)-A-S-H, $\mathrm{CaCO}_{3}, \mathrm{SiO}_{2}$, and hydrotalcite. The aluminum not incorporated into the C-A-S-H might form other reaction products. Hydrotalcite, for example, is one of these secondary products, with reflections observed at $11.4^{\circ}, 22.8^{\circ}, 34.3^{\circ}$ and $46.1^{\circ} 2 \theta$ in Fig. 12. Hydrotalcite possesses a brucite-type layer structure with the interlayer region containing $\mathrm{CO}_{3}{ }^{2-}$ ions and water molecules [45]. The geopolymeric gel appeared to increase with an increase in slag content (M50) which also explains the higher compressive strength achieved in M50. As can be noticed, the PP did not completely participate in the geopolymerization reactions and some of its crystalline phases such as $\mathrm{SiO}_{2}$ remained unchanged in the consolidated matrix. In addition, the presence of alumino-silicate compounds (Si-O-Al network) can be clearly noticed in the M50 paste by peaks corresponding to 33-34 ${ }^{\circ}$ [46]. The absence of crystalline $\mathrm{Ca}(\mathrm{OH})_{2} \mathrm{peaks}$ in the paste samples suggest the occurrence of a preferential reaction between unstable and reactive Ca from portlandite and the alkali silicate solution, likely forming amorphous hydrated gel phases within the geopolymer matrix or acting as an ionic substitution in the network of the alkali-activated material $[47,48]$.

\section{Conclusions}

The physical, mechanical, and microstructural properties of pumice powder and blast furnace slag based geopolymer paste and mortars are investigated. Two types of alkali activators, their concentration, as well as their combination with different ratios of sodium silicate, were considered as the main parameters. Based on the research findings, the following conclusions may be drawn:

1) The use of sodium silicate and potassium hydroxide as an activator for pumice powder and blast furnace slag blend resulted in higher compressive strength compared to sodium hydroxide and sodium silicate. The highest strength at 28 days was observed as $29 \mathrm{MPa}$ in the geopolymer paste P-6K-SS1.0.

2) The gradual increase of the pumice powder ratio in the mix design decreased the density and thermal conductivity, on the other hand, increased the water absorption values of the geopolymer mortars. However, the 
physical properties were insignificantly changed in geopolymer mortars incorporating 60 , 70 , and $80 \%$ of pumice powder in the binder.

3) Thermal conductivity of the geopolymer mortars decreased consistently with the increase in pumice powder ratio and the lowest thermal conductivity coefficient was observed in the M70 mix as $0.558 \mathrm{~W} / \mathrm{mK}$ (slightly lower than M80) which was 45\% lower than the M50 mix.

4) The microstructural analysis supported the higher compressive strength achieved with a higher slag ratio. On the other hand, the pumice powder with higher ratios failed to interact completely in the geopolymeric reactions and rather remained dispersed in the matrix as a filler material. The hollow structure of the unreacted pumice powder particles reduced the strength which may limit its use in higher ratios beyond $50 \%$ when higher mechanical properties are desired.

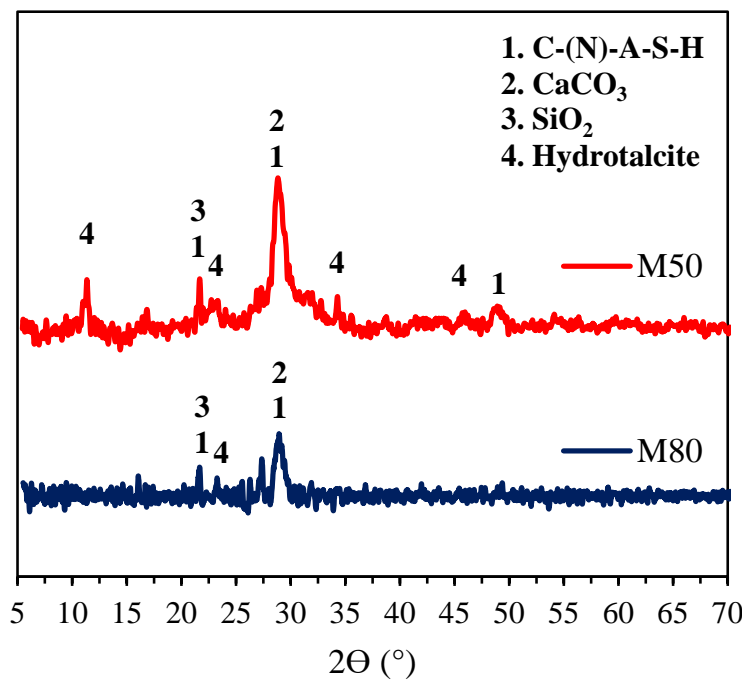

Fig. 12. XRD spectra of M50 and M80 geopolymer paste

\section{Acknowledgements}

This work has been supported by Yildiz Technical University Scientific Research Projects Coordination Unit under project number FYL-2020-3867. The authors also acknowledge Oyak Beton for providing blast furnace slag used in the research.

\section{References}

[1] Scrivener KL, Kirkpatrick RJ. Innovation in use and research on cementitious material. Cement and Concrete Research. 2008;38(2):128-136.

[2] Turner LK, Collins FG. Carbon dioxide equivalent (CO2-e) emissions: A comparison between geopolymer and OPC cement concrete. Construction and Building Materials. 2013;43:125-130.

[3] Statista. Published 2021. Available online: https://www.statista.com/statistics/219343/cement-productionworldwide. (Accessed May 7, 2021).

[4] Gartner E. Industrially interesting approaches to "low-CO2" cements. Cement and Concrete Research. 2004;34(9):1489-1498.

[5] Hasanbeigi A, Price L, Lin E. Emerging energy-efficiency and CO2 emission-reduction technologies for cement and concrete production: A technical review. Renewable and Sustainable Energy Reviews. 2012;16(8):6220-6238.

[6] Damtoft JS, Lukasik J, Herfort D, Sorrentino D, Gartner EM. Sustainable development and climate change initiatives. Cement and Concrete Research. 2008;38(2):115-127.

[7] Davidovits J. Geopolymers: Inorganic polymeric new materials. Journal of Thermal Analysis and Calorimetry. 1991;37(8):1633-1656.

[8] van Deventer JSJ, Provis JL, Duxson P, Brice DG. Chemical research and climate change as drivers in the commercial adoption of alkali activated materials. Waste and Biomass Valorization. 2010;1(1):145-155.

[9] Duxson P, Provis JL, Lukey GC, van Deventer JSJ. The role of inorganic polymer technology in the development of “green concrete.” Cement and Concrete Research. 2007;37(12):1590-1597. 
[10] Tang Z, Li W, Tam VWY, Luo Z. Investigation on dynamic mechanical properties of fly ash/slag-based geopolymeric recycled aggregate concrete. Composites Part B: Engineering. 2020;185:107776.

[11] Hu Y, Tang Z, Li W, Li Y, Tam VWY. Physical-mechanical properties of fly ash/GGBFS geopolymer composites with recycled aggregates. Construction and Building Materials. 2019;226:139-151.

[12] Deb PS, Nath P, Sarker PK. The effects of ground granulated blast-furnace slag blending with fly ash and activator content on the workability and strength properties of geopolymer concrete cured at ambient temperature. Materials and Design. 2014;62:32-39.

[13] Puertas F, Martínez-Ramírez S, Alonso S, Vázquez T. Alkali-activated fly ash/slag cements. Strength behaviour and hydration products. Cement and Concrete Research. 2000;30(10):1625-1632.

[14] Ryu GS, Lee YB, Koh KT, Chung YS. The mechanical properties of fly ash-based geopolymer concrete with alkaline activators. Construction and Building Materials. 2013;47:409-418.

[15] Rajamma R, Labrincha JA, Ferreira VM. Alkali activation of biomass fly ash-metakaolin blends. Fuel. 2012;98:265-271.

[16] Duan P, Yan C, Zhou W. Influence of partial replacement of fly ash by metakaolin on mechanical properties and microstructure of fly ash geopolymer paste exposed to sulfate attack. Ceramics International. 2016;42(2):3504-3517.

[17] Pacheco-Torgal F, Moura D, Ding Y, Jalali S. Composition, strength and workability of alkali-activated metakaolin based mortars. Construction and Building Materials. 2011;25(9):3732-3745.

[18] Buchwald A, Hilbig H, Kaps Ch. Alkali-activated metakaolin-slag blends-performance and structure in dependence of their composition. Journal of Materials Science. 2007;42(9).

[19] Vafaei M, Allahverdi A. High strength geopolymer binder based on waste-glass powder. Advanced Powder Technology. 2017;28(1):215-222.

[20] Khalifa AZ, Cizer Ö, Pontikes Y, et al. Advances in alkali-activation of clay minerals. Cement and Concrete Research. 2020;132:106050.

[21] Marsh A, Heath A, Patureau P, Evernden M, Walker P. Phase formation behaviour in alkali activation of clay mixtures. Applied Clay Science. 2019;175:10-21.

[22] Ibrahim M, Megat Johari MA, Rahman MK, Maslehuddin M. Effect of alkaline activators and binder content on the properties of natural pozzolan-based alkali activated concrete. Construction and Building Materials. 2017; 147:648-660.

[23] Kabay N, Tufekci MM, Kizilkanat AB, Oktay D. Properties of concrete with pumice powder and fly ash as cement replacement materials. Construction and Building Materials. 2015;85:1-8.

[24] Kabay N, Miyan N, Özkan H. Utilization of pumice powder and glass microspheres in cement mortar using paste replacement methodology. Construction and Building Materials. 2021;282:122691.

[25] Karthika RB, Vidyapriya V, Nandhini Sri KV, Merlin Grace Beaula K, Harini R, Sriram M. Experimental study on lightweight concrete using pumice aggregate. Materials Today: Proceedings. 2021;43:1606-1613.

[26] Kabay N, Kizilkanat AB, Tüfekçi MM. Effect of prewetted pumice aggregate addition on concrete properties under different curing conditions. Periodica Polytechnica Civil Engineering. 2016;60(1).

[27] Lynda Amel C, Kadri EH, Sebaibi Y, Soualhi H. Dune sand and pumice impact on mechanical and thermal lightweight concrete properties. Construction and Building Materials. 2017;133:209-218.

[28] Sari D, Pasamehmetoglu AG. The effects of gradation and admixture on the pumice lightweight aggregate concrete. Cement and Concrete Research. 2005;35(5):936-942.

[29] Zeyad AM, Khan AH, Tayeh BA. Durability and strength characteristics of high-strength concrete incorporated with volcanic pumice powder and polypropylene fibers. Journal of Materials Research and Technology. 2020;9(1):806-813.

[30] Tran Q, Ghosh P. Influence of pumice on mechanical properties and durability of high performance concrete. Construction and Building Materials. 2020;249:118741.

[31] Safari Z, Kurda R, Al-Hadad B, Mahmood F, Tapan M. Mechanical characteristics of pumice-based geopolymer paste. Resources, Conservation and Recycling. 2020;162:105055.

[32] Occhipinti R, Stroscio A, Finocchiaro C, et al. Alkali activated materials using pumice from the Aeolian Islands (Sicily, Italy) and their potentiality for cultural heritage applications: Preliminary study. Construction and Building Materials. 2020;259:120391.

[33] Allahverdi A, Mehrpour K, Kani EN. Investigating the possibility of utilizing pumice-type natural pozzonal in production of geopolymer cement. Ceramics Silikaty. 2008;52(1):16.

[34] Lucio-Martin T, Roig-Flores M, Izquierdo M, Alonso MC. Thermal conductivity of concrete at high temperatures for thermal energy storage applications: Experimental analysis. Solar Energy. 2021;214:430442.

[35] Zhao H, Liu F, Yang H. Thermal properties of coarse RCA concrete at elevated temperatures. Applied Thermal Engineering. 2018;140:180-189. 
[36] Kazmi SMS, Munir MJ, Wu Y-F, Lin X, Ahmad MR. Investigation of thermal performance of concrete incorporating different types of recycled coarse aggregates. Construction and Building Materials. 2021;270:121433.

[37] Lee JO, Choi H, Lee JY. Thermal conductivity of compacted bentonite as a buffer material for a high-level radioactive waste repository. Annals of Nuclear Energy. 2016;94:848-855.

[38] Fang G, Bahrami H, Zhang M. Mechanisms of autogenous shrinkage of alkali-activated fly ash-slag pastes cured at ambient temperature within $24 \mathrm{~h}$. Construction and Building Materials. 2018;171:377-387.

[39] Shah SFA, Chen B, Oderji SY, Haque MA, Ahmad MR. Improvement of early strength of fly ash-slag based one-part alkali activated mortar. Construction and Building Materials. 2020;246:118533.

[40] Lee NK, Lee HK. Setting and mechanical properties of alkali-activated fly ash/slag concrete manufactured at room temperature. Construction and Building Materials. 2013;47:1201-1209.

[41] Ye H, Cartwright C, Rajabipour F, Radlińska A. Understanding the drying shrinkage performance of alkaliactivated slag mortars. Cement and Concrete Composites. 2017;76:13-24.

[42] Punurai W, Kroehong W, Saptamongkol A, Chindaprasirt P. Mechanical properties, microstructure and drying shrinkage of hybrid fly ash-basalt fiber geopolymer paste. Construction and Building Materials. 2018;186:62-70.

[43] Marjanović N, Komljenović M, Baščarević Z, Nikolić V, Petrović R. Physical-mechanical and microstructural properties of alkali-activated fly ash-blast furnace slag blends. Ceramics International. 2015;41(1):1421-1435.

[44] Dong M, Feng W, Elchalakani M, Li G (Kevin), Karrech A, May EF. Development of a high strength geopolymer by novel solar curing. Ceramics International. 2017;43(14):11233-11243.

[45] Sun Z, Vollpracht A. Isothermal calorimetry and in-situ XRD study of the $\mathrm{NaOH}$ activated fly ash, metakaolin and slag. Cement and Concrete Research. 2018;103:110-122.

[46] Chindaprasirt P, Rattanasak U. Characterization of the high-calcium fly ash geopolymer mortar with hotweather curing systems for sustainable application. Advanced Powder Technology. 2017;28(9):2317-2324.

[47] Granizo ML, Alonso S, Blanco-Varela MT, Palomo A. Alkaline activation of metakaolin: Effect of calcium hydroxide in the products of reaction. Journal of the American Ceramic Society. 2002;85:225-231.

[48] Yip CK, Lukey GC, van Deventer JSJ. The coexistence of geopolymeric gel and calcium silicate hydrate at the early stage of alkaline activation. Cement and Concrete Research. 2005;35(9):1688-1697.

(C) 2021 by the author(s). This work is licensed under a Creative Commons Attribution 4.0

International License (http://creativecommons.org/licenses/by/4.0/). Authors retain copyright of their work, with first publication rights granted to Tech Reviews Ltd. 